\begin{tabular}{|c|l|}
\hline Title & $\begin{array}{l}\text { Virus induced gene silencing in A ntirrhinum maj us using the Cucumber mosaic virus vector : Functional analysis of the } \\
\text { A INTEGUMENTA (Am-ANT) gene of A. majus }\end{array}$ \\
\hline Author(s) & Kim, Bo Min; Inaba, Jun-ichi; Masuta, Chikara \\
\hline Citation & $\begin{array}{l}\text { Horticulture, Environment, and Biotechnology, 52(2), 176-182 } \\
\text { https://doi.org/10.1007/313580-011-0172-y }\end{array}$ \\
\hline Issue Date & 2011-04 \\
\hline Doc URL & http://hdl.handle.net/2115/48722 \\
\hline Rights & The original publication is available at www.springerlink.com \\
\hline Type & article (author version) \\
\hline File Information & HEB52-2_176-182.pdf \\
\hline
\end{tabular}

Instructions for use 


\title{
Virus Induced Gene Silencing in Antirrhinum majus using the Cucumber Mosaic Virus Vector: Functional Analysis of the AINTEGUMENTA (Am- ANT) Gene in A. majus
}

\author{
Bo Min Kimª , Jun-ichi Inaba ${ }^{\mathrm{a}}$, Chikara Masuta* \\ Research Faculty of Agriculture, Hokkaido University, Kita 9 Nishi 9, Sapporo 060-8589, Japan \\ *Corresponding author: masuta@res.agr.hokudai.ac.jp \\ ${ }^{\mathrm{a}}$ First and second authors equally contributed
}

\begin{abstract}
The Arabidopsis gene AINTEGUMENTA (At-ANT) functions in cell proliferation and organ growth. The ANT protein has two copies of the AP2 domains, R1 and R2. Recently, a partial cDNA sequence of the At-ANT homolog in Antirrhinum majus (Am-ANT) was reported (Delgado-Benarroch et al., 2009). Here, we used virus-induced gene silencing (VIGS) to analyze the function of the reported Am-ANT. We then determine the open reading frame (ORF) of Am-ANT and its predicted amino acid sequence. We induced VIGS using Cucumber mosaic virus (CMV-A1) and suppressed the level of Am-ANT mRNA and noted any phenotypic changes. The function of Am-ANT was very similar to that of At-ANT. The A1:ANTinfected Antirrhinum plants had smaller floral organs and leaves, even though cell sizes were unchanged in flowers and larger in leaves. CMV-based VIGS showed that the cloned Am-ANT gene was indeed functional in cell proliferation and organ growth as observed for At-ANT. In A. majus, CMV vector provide great advantages for analysis of gene functions.
\end{abstract}

Additional key word: AINTEGUMENTA, Cucumber mosaic virus, VIGS 


\section{Introduction}

The AINTEGUMENTA (ANT) protein is involved in cell proliferation in the primordium. The Arabidopsis ANT (At-ANT) protein contains two copies of the AP2 domain (R1 and R2), which is characteristic for floral homeotic genes and transcription factors; it acts as a transcriptional activator, binding to a unique DNA consensus sequence (Nole-Wilson; Krizek, 2000; Krizek, 2003).

The At-ANT gene functions during several stages of reproductive organ development in floral meristems and regulates growth and development in ovules, petals and gynoecia (Elliott et al., 1996; Mizukami and Fischer, 2000; Horiguchi et al., 2006). Inactivation and overexpression of this transcription factor reduces and increases the total cell number in lateral organs, respectively, without changing proliferation rates (Mizukami and Fisher, 2000). The loss of function of At-ANT results in fewer cells, smaller floral organs and smaller leaf sizes. Conversely, plants of Arabidopsis that gain At-ANT function develops enlarged embryonic tissues and shoot organs but without increasing the number of cells. In tobacco, the ANT ortholog, an ANTlike sequence from Nicotiana tabacum (NtANTL), has high similarity to At-ANT (Rieu et al., 2005).

In recent studies, partial cDNA of a putative ANT-like ortholog with the AP2 domains in Antirrhinum majus was cloned using a yeast one-hybrid approach; the open reading frame (ORF) of ANT (Am-ANT) of A. majus was not been determined (Delgado-Benarroch et al., 2009). The reported sequence for $A m-A N T$ is similar to the NtANTL and At-ANT genes. In situ hybridization in A. majus to analyze the expression of Am$A N T$ revealed that $A m-A N T$ was expressed in floral meristems and in early floral organ primordia (DelgadoBenarroch et al., 2009). As floral organs matured, the expression of Am-ANT decreased in sepals at an early stage and in stamens at a late stage. In petals, Am-ANT expression was restricted to the epidermis, particularly in the furrow areas, which rapidly expand to form the palate and lips. In the gynoecium, Am-ANT expression was concentrated in the developing ovules. The timing and location of Am-ANT expression pattern in floral organs was almost the same as that of At-ANT. However, we do not know whether the function of $A m-A N T$ is actually equivalent to that of $A t-A N T$.

A. majus has served as a classic model organism for studies of inheritance and mutation in flowering plants (e.g., Darwin, 1868) and of floral organ development (Hudson et al., 2008). In Arabidopsis, there are various mutant lines to study the genes involved in flower and leaf development and in pigmentation by 
transposon tagging, but mutant tag lines for Antirrhinum majus have not been established yet.

For this reason, we believe that virus-induced gene silencing (VIGS) is a powerful tool for functional analysis of genes in Antirrhinum plants. VIGS has many advantages over the other methods, including that it is rapid and does not require plant transformation (Burch-Smith et al., 2004). A different virus vector is required for each target plant species to induce VIGS efficiently, but a suitable viral vector for $A$. majus has not yet been found (Shang et al., 2007).

In this study, we determined the ORF of $A m-A N T$ and investigated the function of $A N T$ in $A$. majus through knock-down experiments of Am-ANT using Cucumber mosaic virus (CMV)-based VIGS. Because CMV has a wide host range and can infect $A$. majus without causing severe symptoms, The CMV vector can be used in a wide range of plants. The CMV vector, A1 can efficiently induce sequence-specific silencing targeted to endogenous genes (Otagaki et al., 2006, Nagamatsu et al., 2007). A short Am-ANT sequence was cloned into the A1 vector, to create A1:ANT. In this report, we successfully demonstrated that the Am-ANT regulated petal organ sizes using CMV-based VIGS. We concluded that Am-ANT was indeed functionally equivalent to At-ANT. Therefore, the CMV-based VIGS is a powerful tool for studies about the function of $A$. majus genes.

\section{Materials and Methods}

\section{Plant material and growth conditions}

Twenty-day-old plants of Antirrhinum majus 'Floral shower hukusha' were used in these experiments. Seeds were directly sown in peat pellets and grown in a greenhouse at $25^{\circ} \mathrm{C}$ with a 16 -h photoperiod.

\section{Isolation of Am-ANT cDNA}

To isolate the full-length Am-ANT cDNA, we ran 5' and 3' RACE reactions on poly(A)+ RNA of A. majus using the 5'/3' RACE Kit, $2^{\text {nd }}$ Generation (Roche). For the 3' RACE experiment, the following primer pairs were used: AP1/5'-AACATTGGTCGACGAATCTTC-3' and AP2/5'-TTGGTCACGAGTTTGAGCAG-3'). For the 5' RACE experiment, the following primer pairs were used: AP1/5'- 
TGAGCTTCATACCTACCTGTCCAACGA-3' and AP2/5'- CTCCATTTTCAACCATGCATGTGGTT-3').

The resulting PCR products were cloned and sequenced in both directions.

\section{Cloning of the Am-ANT sequence into the CMV-A1 vector}

The 180-bp sequence of Am-ANT was amplified by PCR using primer pair AM-ANT-Stu (5'CGAGGCCTGATCCATGTTGTGGTGTGGTACA-3')/AM-ANT-Mlu,

CGCACGCGTGGTGCATAATTCTTCTCCCAA-3'). The first six nucleotides of the forward primers contain a Stu1 site, and those of the reverse primer contain an Mlu1 site, which were used in the subsequent plasmid construction. After inserting the PCR products into the pGEM-T Easy Vector (Promega, Madison, WI, USA), the Stu1-Mlu1 PCR fragment was inserted at the Stu1 and Mlu1 sites of the AMV-A1 vector (Otagaki et al., 2006). Using these procedures, the fragments of the Am-ANT genes were inserted into the vector in the antisense direction.

\section{In vitro transcription of viral RNA}

The plasmid pCY1, which contains the full-length cDNA of RNA1 of CMV-Y (Suzuki et al., 1991), and the CMV-A1 vector were linearized with Not1, and plasmid pCY3, which contains the full-length cDNA of RNA3 of CMV-Y, was linearized with EcoR1 prior to in vitro transcription. The in vitro transcription reaction was performed as described by Nagamatsu et al. (2007).

\section{Viral inoculation and detection}

Three or four fully expanded leaves of 4-week-old plants were rub-inoculated using carborundum with the sap inocula (in $0.1 \mathrm{M}$ phosphate buffer) from the Nicotiana benthaminana leaves infected with the virus (Otagaki et al., 2006). To localize the distribution of the virus in the infected flower organs or leaves, tissue print blots were prepared, and the virus was detected with anti-CMV antibodies as described by Kim et al. (2008).

\section{Isolation of total RNA and gene expression analysis}


Total RNA was isolated using Trizol reagent (Invitrogen, Tokyo) as described previously (Kim et al. 2008). For real-time PCR, $1 \mu \mathrm{g}$ of the total RNA was used as the template for cDNA synthesis. First strand cDNA was synthesized with a Takara RNA PCR Kit (Takara, Ohtsu, Japan) with oligo (dT) primer. The cDNA was synthesized at $42^{\circ} \mathrm{C}$ for $1 \mathrm{~h}, 99^{\circ} \mathrm{C}$ for $5 \mathrm{~min}$, then $4^{\circ} \mathrm{C}$. Real-time RT-PCR was carried out using a $1-\mu \mathrm{l}$ aliquot of the reaction mixture and SYBR green mixture (Takara) with a DNA Engine Opticon 2 System (MJ Research, Waltham, MA, USA). The PCR cycle was $94^{\circ} \mathrm{C}$ for $30 \mathrm{~s}, 55^{\circ} \mathrm{C}$ for $30 \mathrm{~s}, 72^{\circ} \mathrm{C}$ for $1 \mathrm{~min}$, and $78^{\circ} \mathrm{C}$ for 2 s. This cycle was repeated 40 times. Fluorescence was quantified before and after the incubation at $78^{\circ} \mathrm{C}$ to monitor for the formation of primer-dimers. The primer pairs were AM-ANT5-1 (5'GTACCACACCACAAACATGGAACAGC-3') and AM-ANT3-2 (5'CTCCATTTTCAACCATGCATGTGGTT-3') plus AM-tub5 (5'-AGCGGATCAATGTGTATTTC-3') and AM-tub3 (5'-TTCCGTATAGTGACCTTTCG-3').

\section{Isolation of low-molecular-weight RNA and detection of small interference RNA (siRNA)}

Low-molecular-weight RNA was isolated and Am-ANT siRNA was detected as described by Goto et al. (2003). An Am-ANT gene-specific antisense RNA probe was prepared using the DIG RNA Labeling Mix (Roche, Basel, Switzerland).

\section{Results}

\section{Identification of ANT-like gene in Antirrhinum majus}

To clone the AINTEGUMENTA-like gene (Am-ANT) in Antirrhinum majus, we first conducted rapid amplification of the cDNA ends (3'RACE and 5'RACE) to complete the ORF beyond the partial cDNA sequence for Am-ANT reported by Delgado-Benarroch et al. (2009). The full-length cDNA of Am-ANT is 2,148 bp long, of which 1,581 bp encode a protein of 526 amino acids; the coding sequence is $29 \%$ and $52 \%$ identical at the nucleotide level to the At-ANT and the NtANTL, respectively (Fig 1a).

An amino acid alignment of the related proteins from Arabidopsis and tobacco showed high sequence conservation between the two AP2 domains (R1 and R2), which are characteristic of ANT proteins. The 
overall identity of the predicted amino acid sequence was $47 \%$ for Arabidopsis (At-ANT), and 63\% for tobacco (NtANTL).

The At-ANT gene is expressed in various organs such as the leaf, shoot and flower (Klucher et al., 1996). $A m-A N T$, however, has so far been shown to be expressed in the flower; whether Am-ANT mRNA is also presence in the leaf has been unclear. We, therefore, first performed reverse transcription polymerase chain reaction (RT-PCR) and confirmed that $A m-A N T$ was expressed in both the flower and leaf (Fig 1c), suggesting that $A m-A N T$ may have the same function as At-ANT. To further demonstrate that $A m-A N T$ has a function similar to that of At-ANT, which regulates growth and development of the flower and leaf, we analyzed the phenotype of the plants in which Am-ANT mRNA was repressed by VIGS. For VIGS to target Am-ANT, the CMV-A1 vector (A1) was used (Otagaki et al., 2006). The 180-bp sequence of the Am-ANT cDNA was cloned into the A1 vector in the antisense orientation (A1:ANT, Fig 1b). The resulting A1:ANT virus was used to inoculate 4-week-old Antirrhinum plants. At 10 days after inoculation, a weak mosaic symptom was observed in Antirrhinum leaves (Fig s1). Viral infection was confirmed with an enzyme-linked immunosorbent assay (ELISA). Tissue-printing using CMV-specific antibodies showed that A1:ANT was distributed throughout the tissues of flower and leaf in A. majus (Fig 2).

\section{Reduction in flower and leaf sizes after infection with A1:ANT}

The size of the flowers and leaves of the plants inoculated with A1 (empty vector) and those inoculated with buffer (mock) did not clearly differ, indicating that inoculation with A1 does not influence the size of the flowers or leaves (Table 1). On the other hand, flower and leaf sizes on the Antirrhinum plants infected with A1:ANT were clearly reduced relative to the mock- and A1-inoculated plants (Fig 3A-F, Fig 4A-C). The length and width of dorsal petals were smaller than those of the mock- or A1-inoculated plants. The lengths of the dorsal petals, stamens and gynoecia were visibly reduced by $21.5 \%, 12.9 \%$ and $6.7 \%$, respectively, compared with the A1-inoculated Antirrhinum plants. The leaf length was also reduced by $22.7 \%$ compared to the control (Table 1).

In $A$. thaliana, knock-out of $A N T$ resulted in a decrease in organ size through the reduction of the cell number, despite an increase in cell size in the leaf and flower. The flower organ sizes of the plants infected 
with A1:ANT were smaller than those of the mock- or the A1-inoculated plants. When the cell sizes in flowers and leaves of the plants inoculated with A1:ANT were analyzed, the size of conical cells in the A1:ANT-inoculated plants were similar to those of mock- or empty-vector-inoculated plants. In contrast to epidermal cells of the flower, those of the leaf were larger than those of the control plants although the cell shapes did not change (Fig 3G-I, Fig 4D-F).

\section{Reduction in the ANT mRNA levels and production of small RNAs}

To confirm that the observed phenotypes were actually due to the VIGS of the Am-ANT gene, we analyzed the level of the Am-ANT mRNA by real-time RT-PCR (Fig 5a). The mRNA levels decreased in A1:ANTinfected plants; in the flower, the levels were reduced by $77 \%$ of the levels in the controls. The level in the leaves decreased by $21 \%$.

Because the production of short interfering RNA (siRNA) is a hallmark for RNA silencing (Hamilton and Baulcombe, 1999), we used a gel blot analysis to detect siRNAs to the Am-ANT genes (Fig 5b). In the Antirrhinum plants inoculated with A1:ANT, siRNAs corresponding to the sequence of the Am-ANT genes were detected. These results suggested that the decrease in flower or leaf size was indeed induced by VIGS of the $A m-A N T$ genes.

\section{Discussion}

In this study, we conducted a functional analysis of Am-ANT using CMV-based VIGS. A previous study shows that $A m-A N T$ is strongly expressed in the early floral organ primordia and preferentially expressed in the ovules during late flower development (Delgado-Benaroch et al., 2009). In the present study, the Am$A N T$ transcripts were detected not only in the flower but also in leaves, suggesting that $A m-A N T$ can function in both tissues. A1:ANT-inoculated plants had smaller flowers and leaves. The dorsal petal was smaller, and the stamens and the gynoecium were shorter. Although Delgado-Benaroch et al. (2009) showed strong expression of $A m-A N T$ in the ovules, the size of the gynoecium did not change in A1:ANT-inoculated plants. In Arabidopsis, At-ANT knock-out mutants had abnormal morphology of the flower and nonfunctional gynoecium (Elliott et al., 1996), suggesting that much stronger suppression of Am-ANT may be needed to 
induce drastic changes in size and morphology in gynoecium. Here, we show that knock-down of Am-ANT resulted in smaller floral organs and leaves. The CMV vector has the ability to knock-down specific gene in A. majus.

What contributes to the reduced size of the plant organs after the knock-down of Am-ANT? Plant organ size is generally influenced by cell size and cell number (Mizukami and Fisher, 2000, Mizukami, 2001). Using light microscopy, we investigated whether a reduction in cell size or number contributed more to the size reduction. In plants infected with A1:ANT, the cell size of the dorsal petals was unchanged, but increased in leaves relative to the mock- and the vector-inoculated plants. This observation is essentially consistent with the previous report by Mizukami and Fisher (2000) although they also found that cell size increased in floral organs. Other than ANT, some other factor(s) must determine cell size in A. majus. If there is such a factor, the knock-down of $A m-A N T$ may not necessarily result in cell enlargement in petal. At-ANT therefore can control plant organ size and cell number by regulating gene expression for cell proliferation in developing organ primordia (Elliott et al., 1996; Klucher et al., 1996; Krizek, 1999; Mizukami and Fischer, 2000). This is supported by the observation that the knock-out mutant of At-ANT developed smaller lateral organs, and that leaves and floral organ had fewer cells than wild type (Elloitt et al., 1996; Klucher et al., 1996; Baker et al., 1997; Schneitz et al., 1997). Considering these results, we also conclude that Am-ANT has the same function as At-ANT in affecting cell number and plant organ size.

In A. majus, the knock-down of gene expressions for analysis of their function was performed by Agroinfiltration (Shang et al., 2007). However, Agrobacterium infection per se may cause severe damage to affect $A$. majus plants growth. Because VIGS is an easy way to knock-down specific genes, several viral vectors have been used in this manner in many plant species. But a suitable virus vector for VIGS had not been developed for Antirrhinum (Shang et al., 2007) until recently, when a Tobacco rattle virus (TRV)-based vector was developed to analyze gene function in A. majus (Preston and Hileman, 2010). However, the infectious pTRV clone must be integrated into A. majus to establish TRV infection, and the transformation efficiency is not very high (Preston and Hileman, 2010).

On the other hand, CMV-A1 can infect A. majus by mechanical inoculation. In addition, CMV-A1 caused only mild mosaic on the infected A. majus. Silencing of Am-ANT in this study clearly reduced floral organ 
size and cell numbers without causing severe symptoms. We therefore conclude that VIGS using the CMVA1 vector is an efficient tool for the functional analysis of endogenous genes in A. majus.

\section{Literature Cited}

Baker, S.C., Robinson-Beers, K., Villanueva, J.M., Gaiser, J.C. and Gasser, C.S. 1997. Interactions among genes regulating ovule development in Arabidopsis thaliana. Genetics 145:1109-1124.

Burch-Smith, T.M., ANDERSON, J.C., MARTIN, G.B. and DINESH-KUMAR, S.P. 2004. Applications and advantages of virus-induced gene silencing for gene function studies in plants. The Plant J. 39 734-746.

Darwin, C.R. 1868. Variation of animals and plants under domestication. John Murray, London.

Delgado-Benarroch, L., Causier, B., Weiss, J. and Egea-Cortines, M. 2009. FORMOSA controls cell division and expansion during floral development in Antirrhinum majus. Planta 229:1219-1229.

Elliott, R.C., Betzner, A.S., Huttner, E., Oakes, M.P., Tucker, W.Q., Gerentes, D., Perez, P. and Smyth, D.R. 1996. AINTEGUMENTA, an APETALA2-like gene of Arabidopsis with pleiotropic roles in ovule development and floral organ growth. Plant Cell 8:155-168.

Goto, K., Kanazawa, A., Kusaba, M. and Masuta, C. 2003. A simple and rapid method to detect plant siRNAs using nonradioactive probes. Plant Mol Biol Rep 21:51-58.

Hamilton, A.J. and Baulcombe, D.C. 1999. A species of small antisense RNA in posttranscriptional gene silencing in plants. Science 286:950-952.

Horiguchi, G., Ferjani, A., Fujikura, U. and Tsukaya, H. 2006. Coordination of cell proliferation and cell expansion in the control of leaf size in Arabidopsis thaliana. J. Plant Res. 119:37-42.

Hudson, A., Critchley, J. and Erasmus, Y. 2008. The Genus Antirrhinum (Snapdragon): A Flowering Plant Model for Evolution and Development. Cold Spring Harb Protoc pdb.emo100.

Kim, B., Masuta, C., Matsuura, H., Takahashi, H. and Inukai, T. 2008. Veinal necrosis induced by Turnip mosaic virus infection in Arabidopsis is a form of defense response accompanying HR-like cell death. MPMI 21:260-268.

Klucher, K.M., Chow, H., Reiser, L. and Fischer, R.L. 1996. The AINTEGUMENTA gene of Arabidopsis required for ovule and female gametophyte development is related to the floral homeotic gene APETALA2. 
Plant Cell 8:137-153.

Krizek, B.A. 1999. Ectopic expression of AINTEGUMENTA in Arabidopsis plants results in increased growth of floral organs. Dev. Genet. 25:224-236.

Krizek, B.A. 2003. AINTEGUMENTA utilizes a mode of DNA recognition distinct from that used by proteins containing a single AP2 domain. Nucleic Acids Res. 31:1859-1868.

Mizukami, Y. and Fischer, R.L. 2000. Plant organ size control: AINTEGUMENTA regulates growth and cell numbers during organogenesis. PNAS 97:942-947.

Mizukami, Y. 2001. A matter of size: developmental control of organ size in plants. Curr. Opin. Plant Biol 4:533-539.

Nagamatsu, A., Masuta, C., Senda, M., Matsuura, H., Kasai, A., Hong, J.S., Kitamura, K., Abe, J. and Kanazawa, A. 2007. Functional analysis of soybean genes involved in flavonoid biosynthesis by virus induced gene silencing. Plant Biotechnol. 5:778-790.

Nole-Wilson, S. and Krizek, B.A. 2000. DNA binding properties of the Arabidopsis floral development protein AINTEGUMENTA. Nucleic Acids Res. 28:4076-4082.

Otagaki, S., Arai, M., Takahashi, A., Goto, K., Hong, J.S., Masuta, C. and Kanazawa, A. 2006. Rapid induction of transcriptional and post-transcriptional gene silencing using a novel Cucumber mosaic virus vector. Plant Biotechnol. 23:259-265.

Preston, J.C. and Hileman, L.C. 2010. SQUAMOSA-PROMOTER BINDING PROTEIN 1 initiates flowering in Antirrhinum majus through the activation of meristem identity genes. The Plant J. 62:704-712.

Rieu, I., Bots, M., Mariani, C. and Weterings, K.A.P. 2005. Isolation and expression analysis of a tobacco AINTEGUMENTA ortholog (NtANTL). Plant Cell Physiol. 46:803-805.

Schneitz, K., Hülskamp, M., Kopczak, S.D. and Pruitt, R.E. 1997. Dissection of sexual organ ontogenesis: a genetic analysis of ovule development in Arabidopsis thaliana. Development 124:1367-1376.

Shang, Y., Schwinn, K.E., Bennett, M.J., Hunter, D.A., Waugh, T.L., Pathirana, N.N., Brummell, D.A., Jameson, P.E. and Davies, K.M. 2007. Methods for transient assay of gene function in floral tissues. Plant Methods 3:1.

Suzuki, M., Kuwata, S., Kataoka, J., Masuta, C., Nitta, N. and Takanami, Y. 1991. Functional analysis of 
deletion mutants of Cucumber mosaic virus RNA3 using an in vitro transcription system. Virology 183:106-113.

\section{Figure legends}

Fig. 1. Identification of the full-length cDNA of Am-ANT. A, Nucleotide sequence of the full-length cDNA clone of Am-ANT. The 5' and 3' nontranslated regions are in lower case, and the ORF is in capitals. Stop codons are marked by stars. The Am-ANT protein is shown in red. The primers to amplify the A1:ANT inserted region are indicated by underlines. The black lines indicate two copies of AP2, R1 and R2 domains. B, Schematic representation of the CMV vector construct containing an Am-ANT cDNA. CMV has tripartite single-stranded sense RNAs (RNAs 1-3). The 193-bp fragment of $A m-A N T$ was inserted into the cloning site of the A1 vector (A1-ANT). C, Expression levels of $A m-A N T$ in different tissues of flower and leaf in A. majus. The Am-ANT mRNA levels were normalized by the $\beta$-tubulin mRNA levels. Error bars are standard errors obtained from three replicates.

Fig. 2. Symptoms induced by A1:ANT in A. majus. A weak mosaic symptom was observed in the A1-ANT- and A1-inoculated plants.

Fig. 3. Immunoblot detection of A1:ANT in Antirrhinum majus. Four-week-old plants of $A$. majus 
were inoculated mechanically with A1:ANT. Note that A1:ANT spread into the entire plants.

Fig. 4. Changes in petal phenotype induced by the A1:ANT infection in A. majus. Flowers in the plants inoculated with phosphate buffer (mock, left), A1 (center) and A1:ANT (right) were compared: longitudinal section (A), lateral view (B), dorsal view (C) and ventral petal (D). Petal sizes are represented as the length and width in mock-, A1- and A1:ANT-inoculated plants (E, F). The means for 20 plants are shown. Error bars are standard errors. Light micrographs of conical petal cells $(\mathrm{G}-\mathrm{H})$.

Fig. 5. Changes in leaf phenotype in A. majus induced by A1:ANT infection. A, Leaves of plants inoculated with phosphate buffer (mock, left), A1 (center) and A1:ANT (right) were compared for change in leaf morphology. Leaf size represented as the length and width in control plants or those inoculated with A1 or A1:ANT (B, C). The means for 20 plants are shown. Error bars are standard errors. Light micrographs of leaf cells (D-F).

Fig. 6. Levels of Am-ANT mRNA and siRNAs in A. majus. A, Quantitative RT-PCR was performed to analyze the $A m-A N T$ mRNA level in leaf and flower. The mRNA levels were normalized using the $\beta$-tubulin mRNA level. The value of the A1-inoculated plant was set at 1 . Data represent means with standard errors obtained from three replicates. B, Accumulation of siRNAs corresponding to the Am-ANT sequence in the A1:ANT-inoculated plants. Ethidium-bromide-stained 5S RNA and tRNA bands in the bottom panel indicate that an equal amount of the small RNA fraction was loaded. 
Table 1 Size of various floral parts of Antirrhinum plants after inoculation with phosphate buffer (mock), A1 or A1:ANT

\begin{tabular}{lcccc}
\hline Variable $(\mathrm{mm})$ & Mock & A1 & A1:ANT & Decrease (\%) \\
\hline Dorsal petal length & $28.1 \pm 0.2$ & $28.7 \pm 0.5$ & $22.5 \pm 0.2$ & 21.53 \\
Dorsal petal width & $33.4 \pm 0.2$ & $32.2 \pm 0.2$ & $26.1 \pm 0.2$ & 18.73 \\
Tube length & $16.0 \pm 0.2$ & $13.1 \pm 0.4$ & $13.9 \pm 0.1$ & -6.16 \\
Tube width & $11.5 \pm 0.1$ & $10.5 \pm 0.1$ & $8.6 \pm 0.1$ & 8.77 \\
Stamen length & $25.3 \pm 0.3$ & $23.2 \pm 0.2$ & $20.2 \pm 0.1$ & 12.88 \\
Gynoecium length & $18.3 \pm 0.3$ & $17.0 \pm 0.3$ & $15.8 \pm 0.1$ & 6.66 \\
\hline
\end{tabular}

$\%$ : Proportion of decrease in size (1 - A1:ANT / A1) X 100 


\section{A}

agtgagtttcttgagggagtgttcaaaaacatgaaatgattactataattcttcccaatcattgatttgccttgaacaacactaaagagaaaagaaaaaaatcacatcttttgtg tcttgtaaaacttgtgaaactcaacaaattaagatgaagtcctccaatgatgagaacaatggcaacaactggcttggattttcactctctcaccccacatgaaaatggaagctct cctacttcagaaagcttctatcttcatcttccactcacaattgctatgaaatggtgactttaactctcatttgtcagttATGCCTCTTAAGTCAGATGGGTCCCTCTGC ATAATGGAAGCTCTCTCTGGATCACATTCAGAAGGTATGGTGCATAGTTCTTCTCCCAAACTTGAAGACTTTTTGAGTGGTGCTACAATO $1 M E A$ L G S H S E G M V H S S S P K L E D F L S G A T M GGTACACATCAGTATTCATCTCAACAAAGAGATGCTGCAATGTTTCTAAGCTTAGAGAGTAGTGCTTATTTTAACCAGCAGCAAAACCAC G T TATTACTCTGCTCTTAACTACAATACTATGTACCACACCACAAACATGGAACAGCATAACACTCAGAATGTTCCACAAATGTCTGAGAAT Y Y S A L N Y N T M Y H T N M E Q H N T Q N V P Q M S E N GAAATCCCTTGTCTGAAAACATGGATTGAGCAGAACCATGCACTTGAACAACAACAACACCACCAGGTTCATAATAATCATAATAGTACA $\begin{array}{llllllllllllllllllllllllllllll}E & I & P & C & L & K & T & W & I & E & Q & N & H & A & L & E & Q & Q & Q & H & H & Q & V & H & N & N & H & N & S & T\end{array}$ ACCACATGCATGGTTGAAAATGGAGGCAAAATGGGGTGTGGAGATTTGCAGTCTTTGAGCTTGTCAATGAGTAGTCCTGTTTCTCAGTCC T T C M V E N G G K M G C G D L Q S L S L S M S S P V S Q S S C V V A S R Q I P T D T T E V A L T K R G S E K

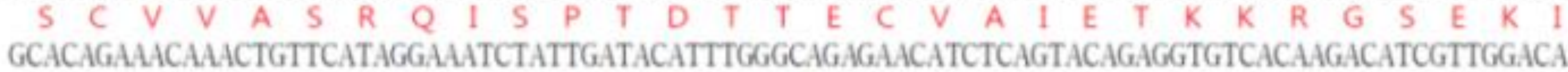

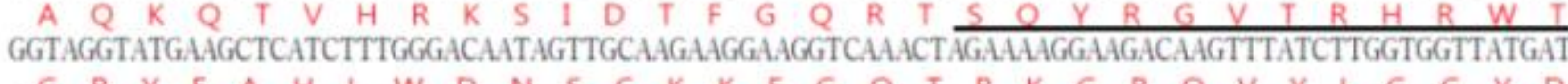
ATGGAAGAGAAAGCTGCAAGAGCATATGATCTTGCTGCGCTGAAATATTGGGGTCCTTCTACTCACATAAACTTTCCATCAG.AGAACTAC $M E$ E K A A R A Y D L A A L K Y W G P S T H I N F P S E N Y CAGCAAGAACTTGAGGAATGAAAAACATGAGCCGACAGGAATGTGTTGCTCACTTGAGAAGGAAAAGTAGTGGATTTTCTAGAGGAGCC Q $Q$ Q E L L E E M N K N M M S R TCGATGTACAGAGGCGTTACAAGGCATCATCAGCATGGTAGATGGCAGGCAAGGATCGGCCGAGTTGCCGGAAACAAGGACCTCTACCTT

$\frac{5}{\text { GGAACTTTCAGCACGCAGGAGG.AGCGGCCGAAGCGTACGATATTGCTGCAATCAAGTTCAGGGGTGCAAACGCGGTCACAAATTTTGAC }}$

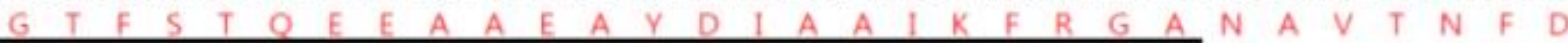
ATATCTCGCTACGACGTTGAGAAAATCATGGCAAGCAATACTCTGCCTACGGGCGACATAGCTAGGCGAAACAAAGAGCCTGAGCCTAAT S R Y D V E K l M A S N T L P T G D I A R R N K E P E P N GCAGAGGTGGCAGCCATTGGATACAAATCCACACCCCAGAGAAACGACGAATCAGTTGGCATAAAGACAATGAACGACGCAAACTACCAA $\begin{array}{llllllllllllllllllllllllllllll}A & E & V & A & A & I & G & Y & K & S & T & P & Q & R & N & D & E & S & V & G & I & K & T & M & N & D & A & N & Y & Q\end{array}$ AACTCGTCTTTCTCGGTAGCTCTGCATGATTTGATTGGCATTGGTTCTACTCAAACATTGGTCGACGAATCTTCAACTTCCCTGGCACCC N S S F S V A L H D L I G I G S T Q Q T L V D E S S T S L A P O AAGCCTAGTCATGTAGAGAACAAGTTCATCAACCCCTCTAGTCAAGTGAATCCTTGGTTTCCACTCACTATGACTCACTTGCCCGTTTTT $K$ K S H V E N K F I N P S S Q Y N P W F P L T M T H L P V F GCTGCATGGGATGATGCATAAtctgccttagaattatggttagctagctattctgttgtaagggtaatttggttatgacattgggatatcaatggagggacaagagtgg A $A$
gatccattratctttccatgacta

atctctaatgattaaattcttgtgtaaaaaaaaaaaaa

\section{B A1:ANT}

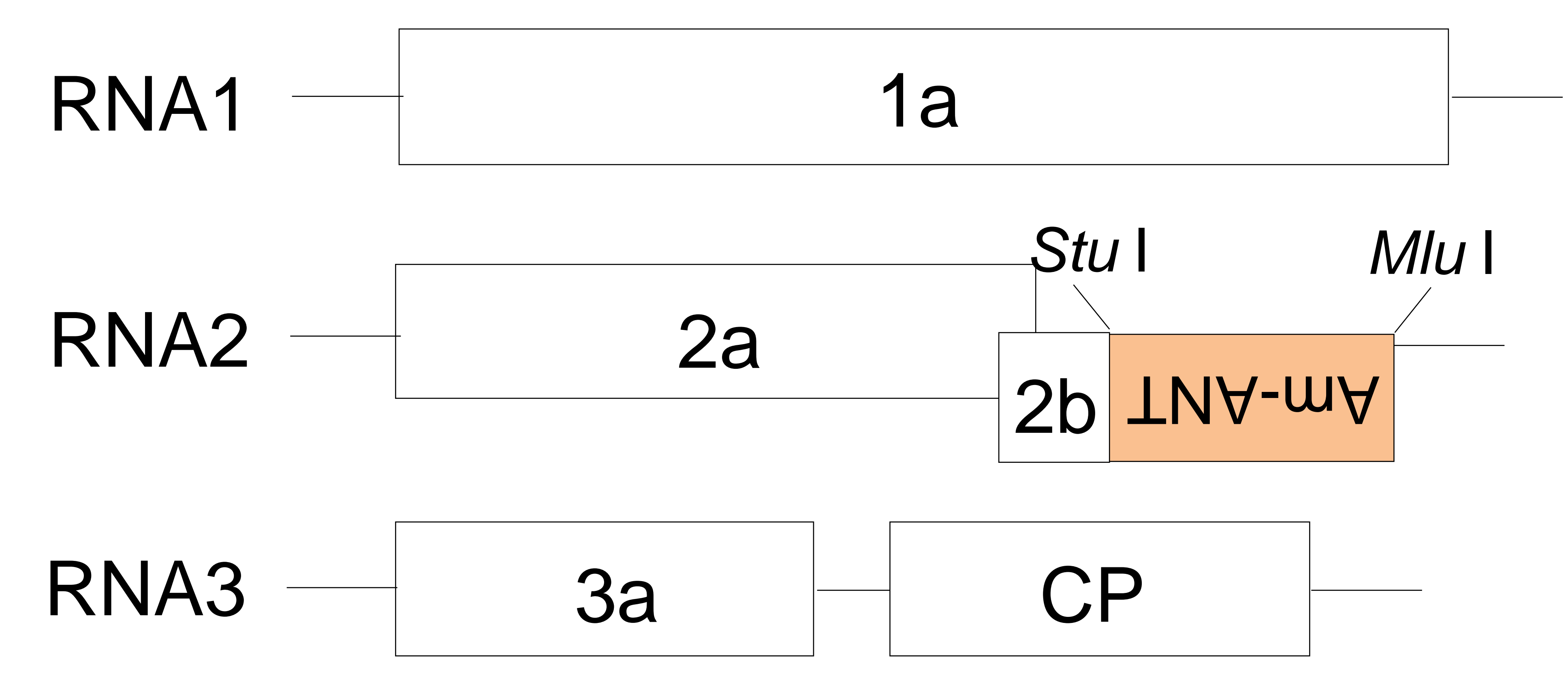

C

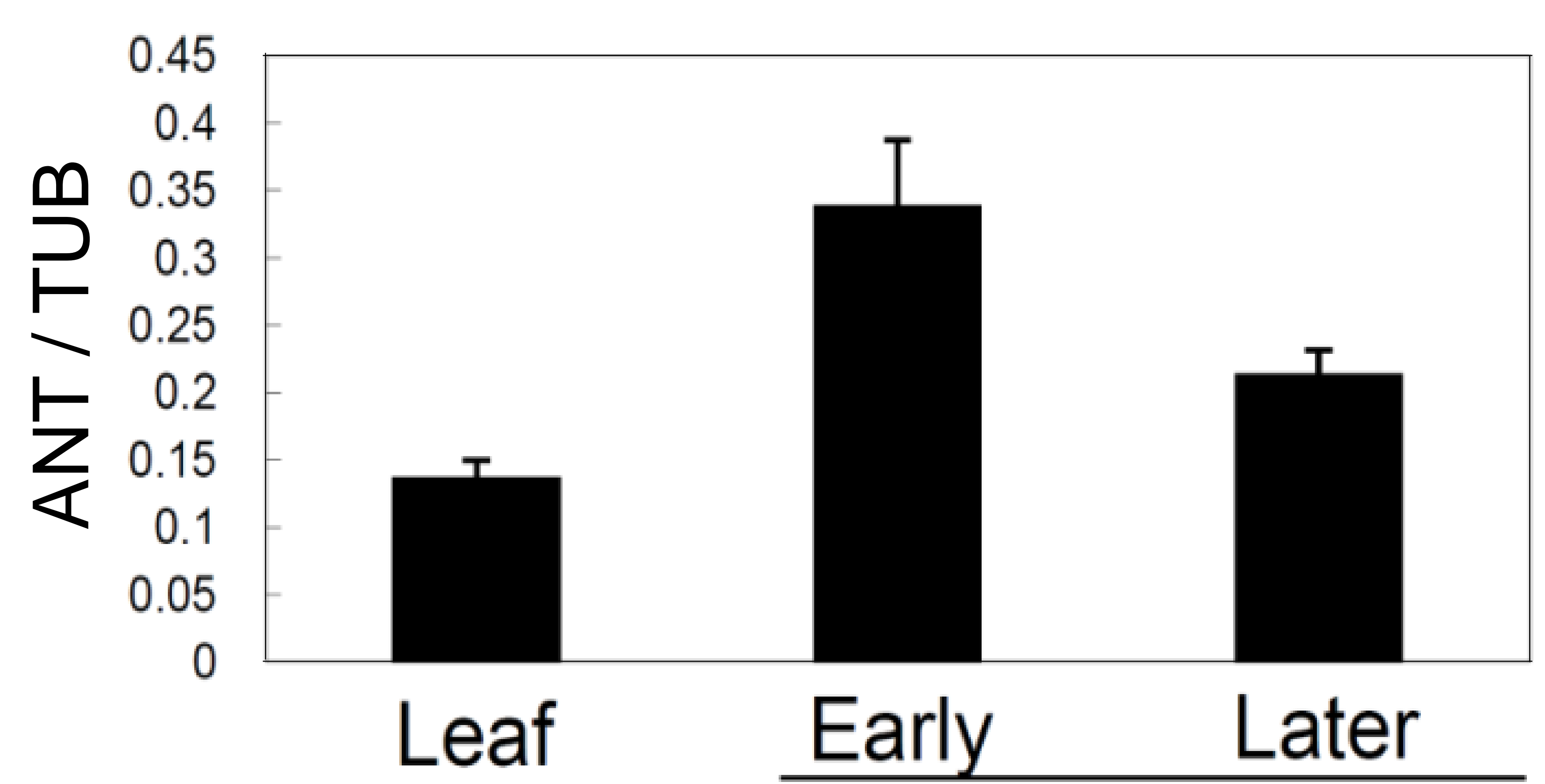

Flower stage 


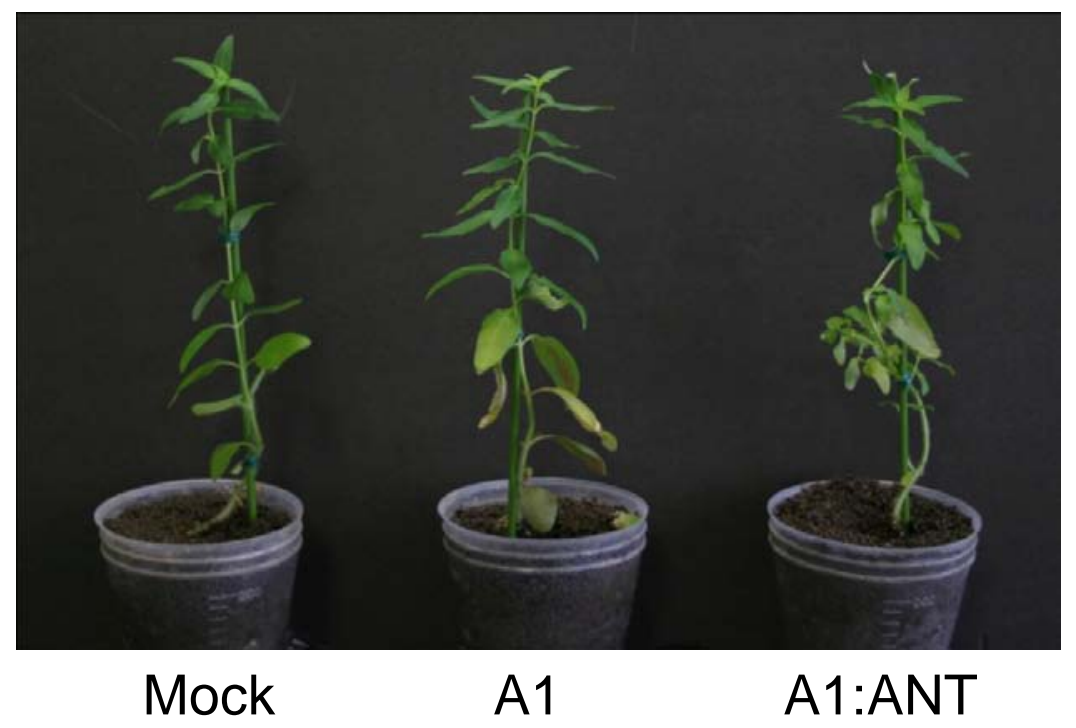




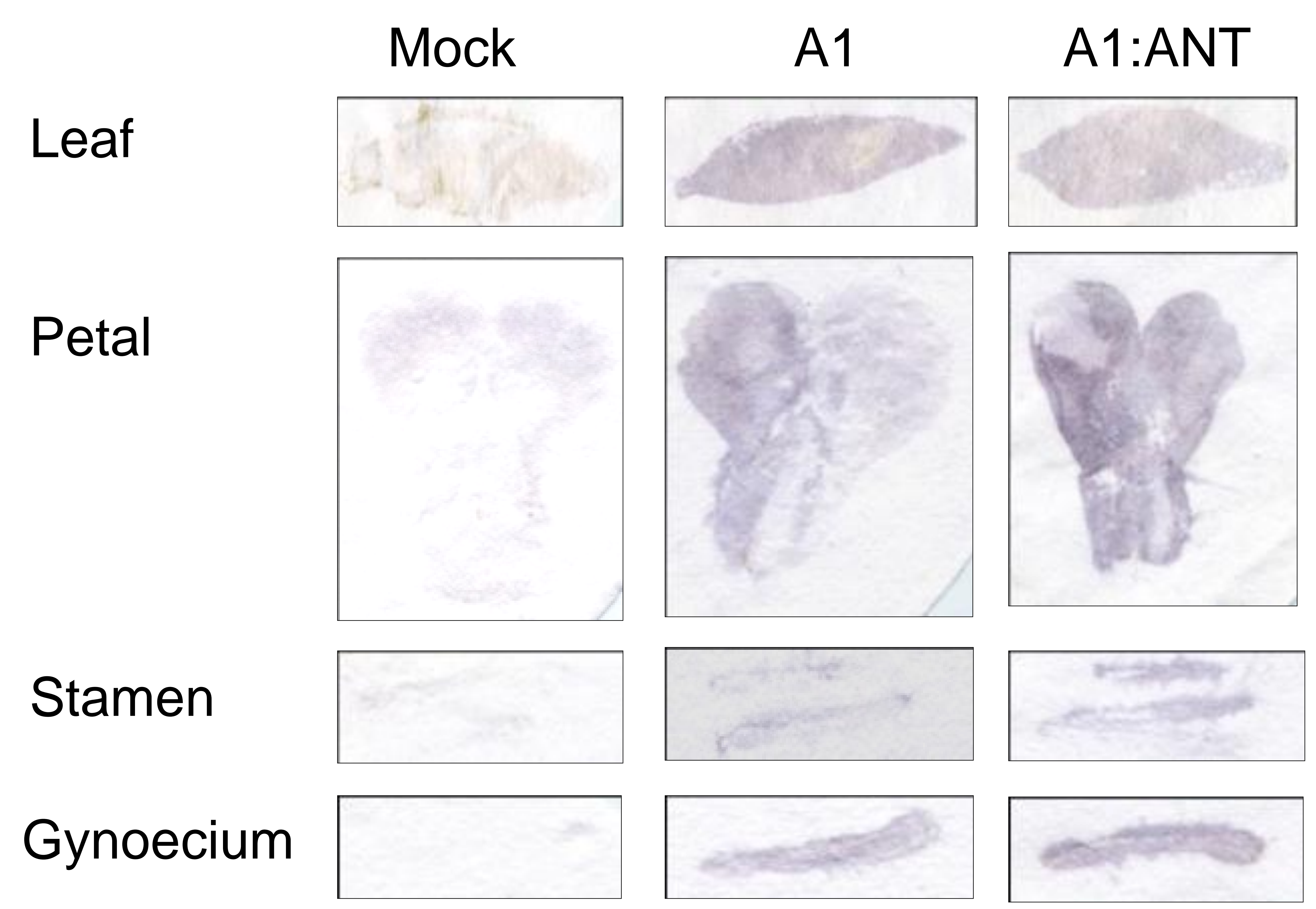


A

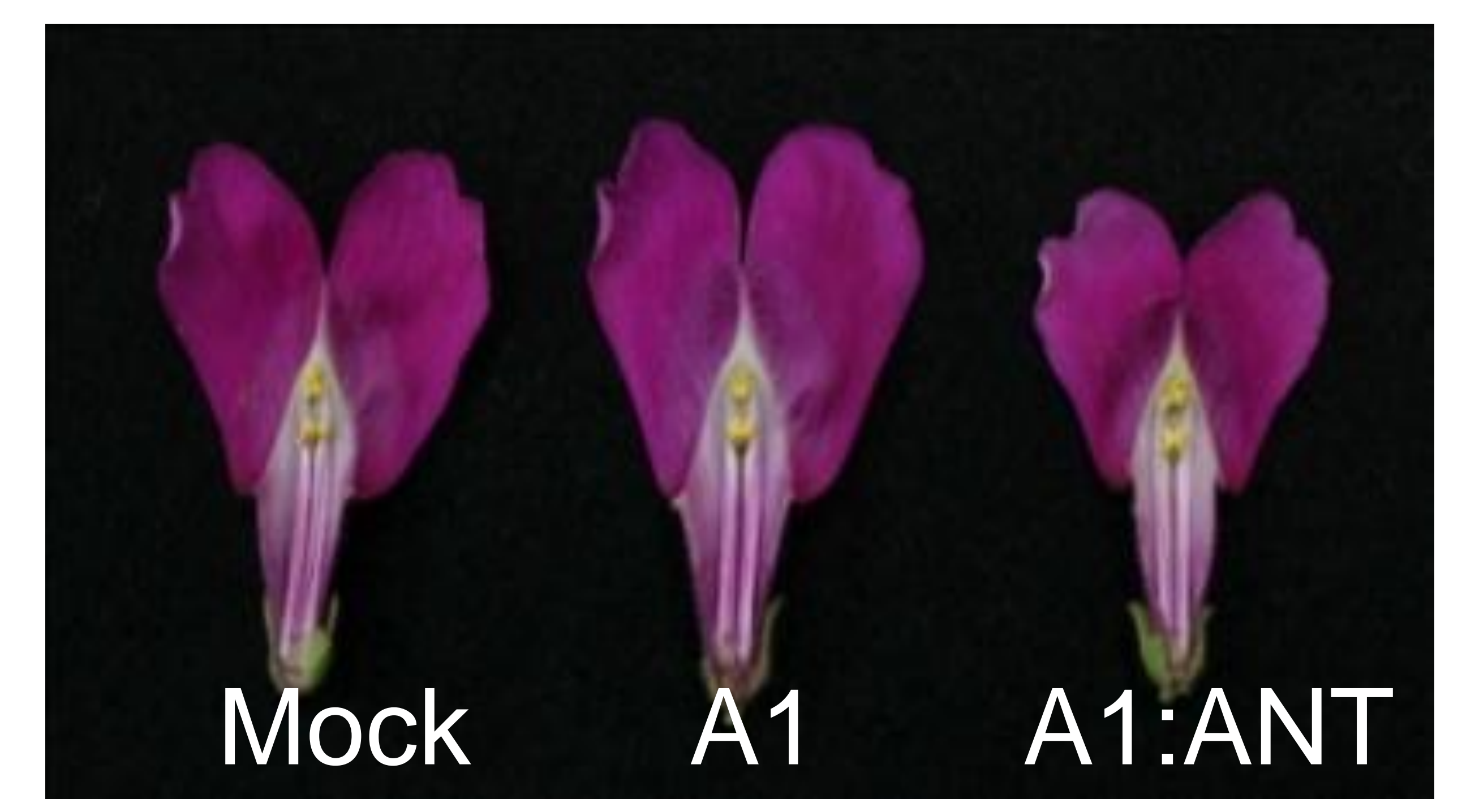

C

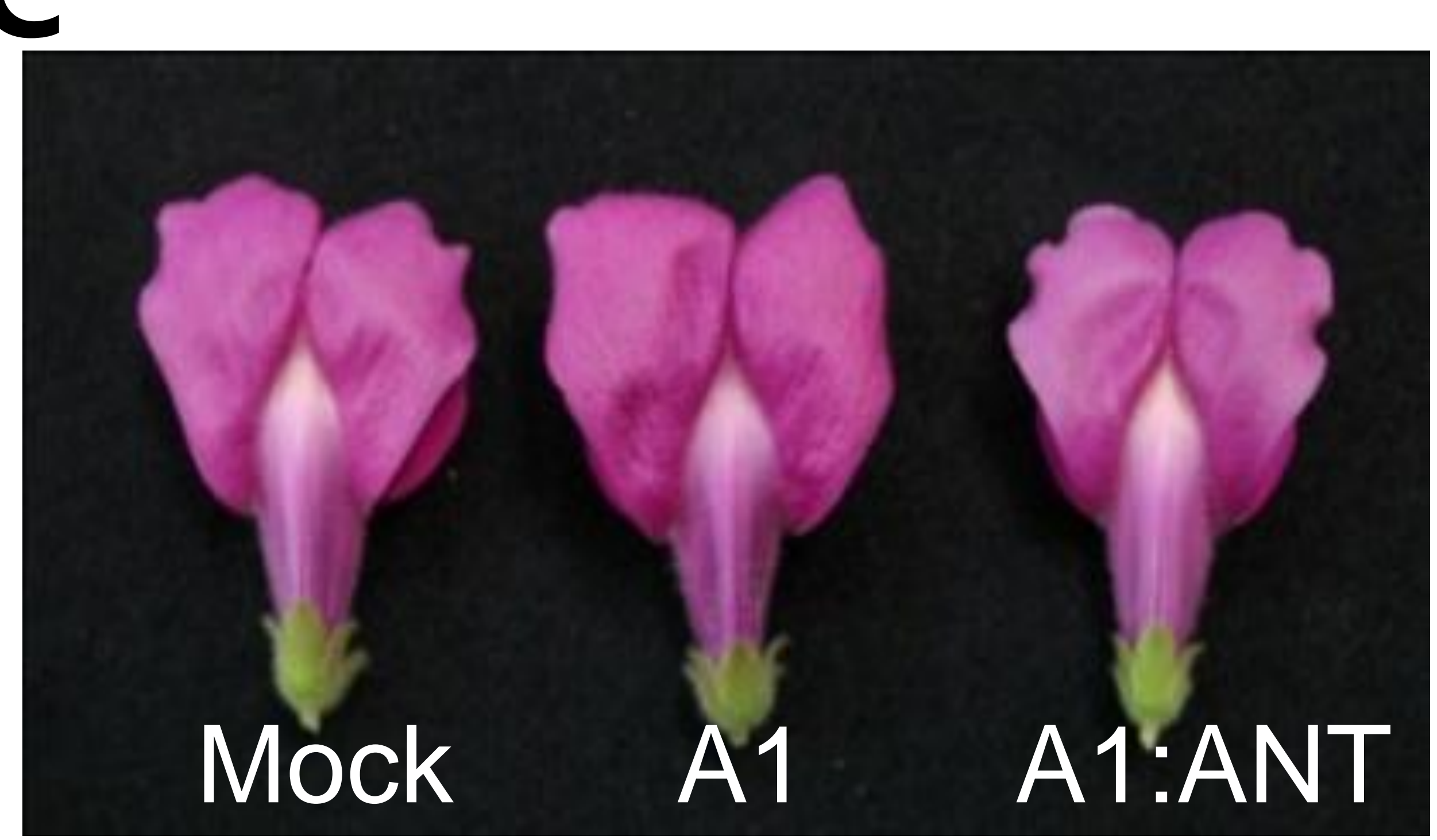

E

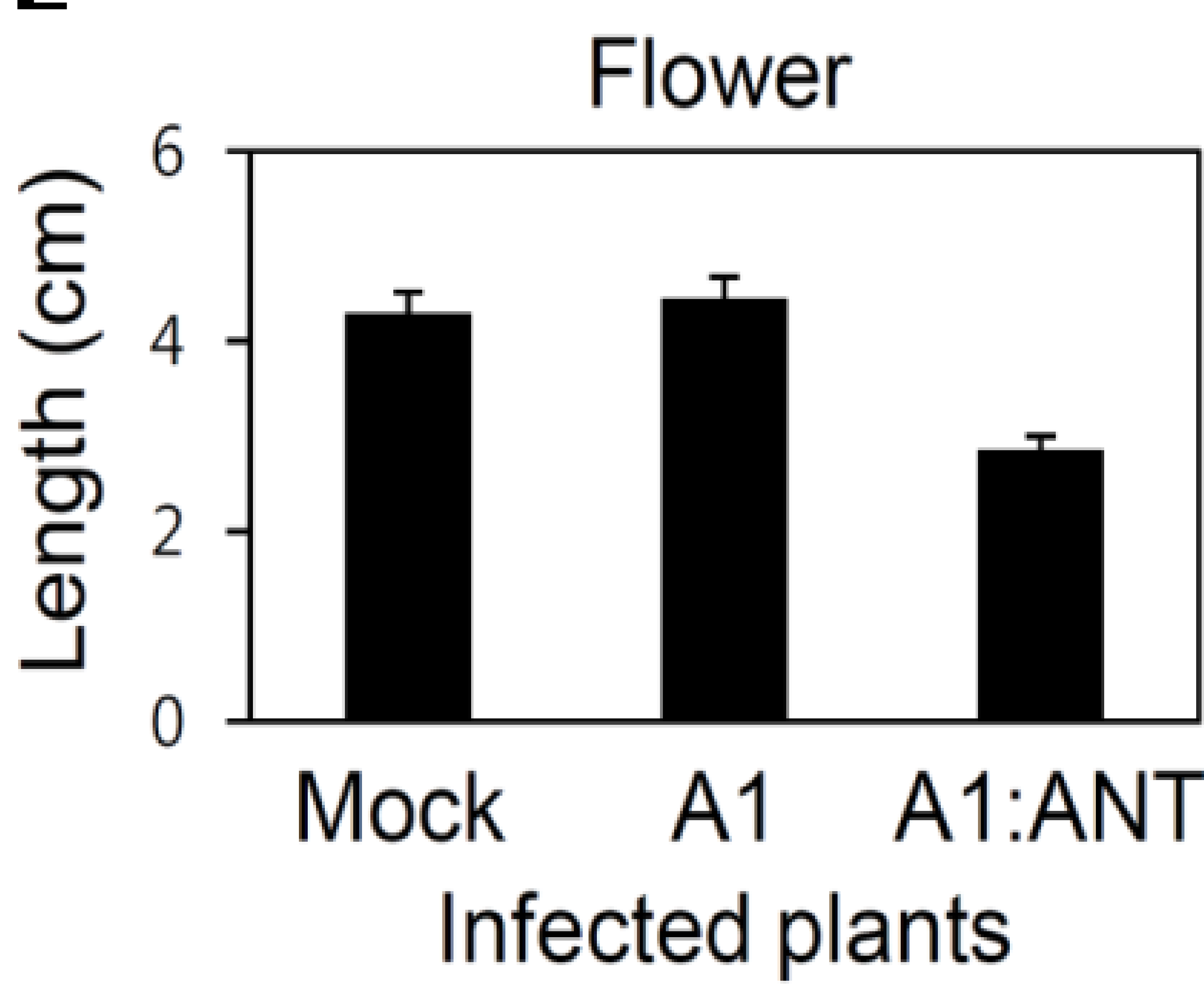

G

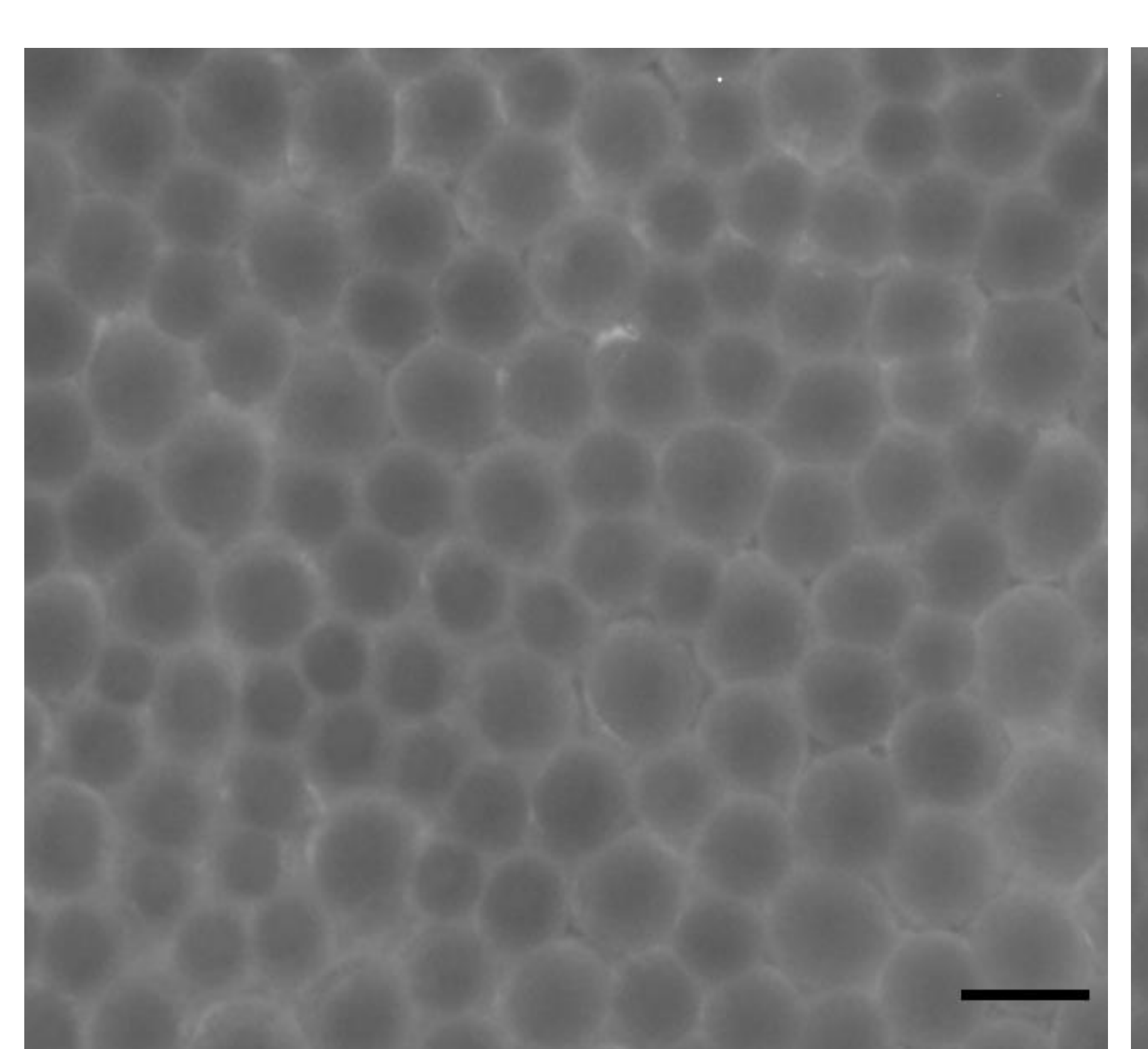

Mock
B

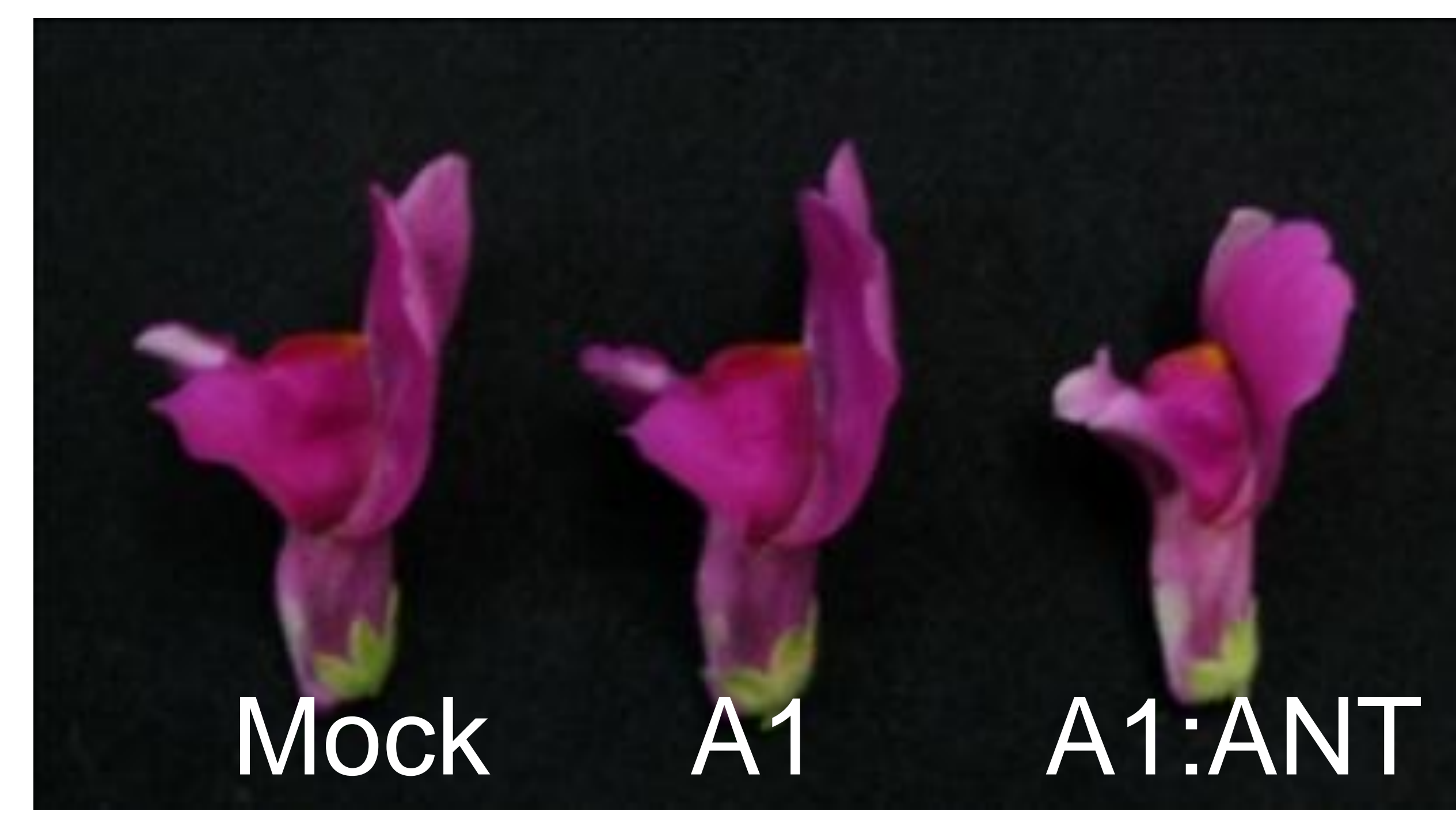

D

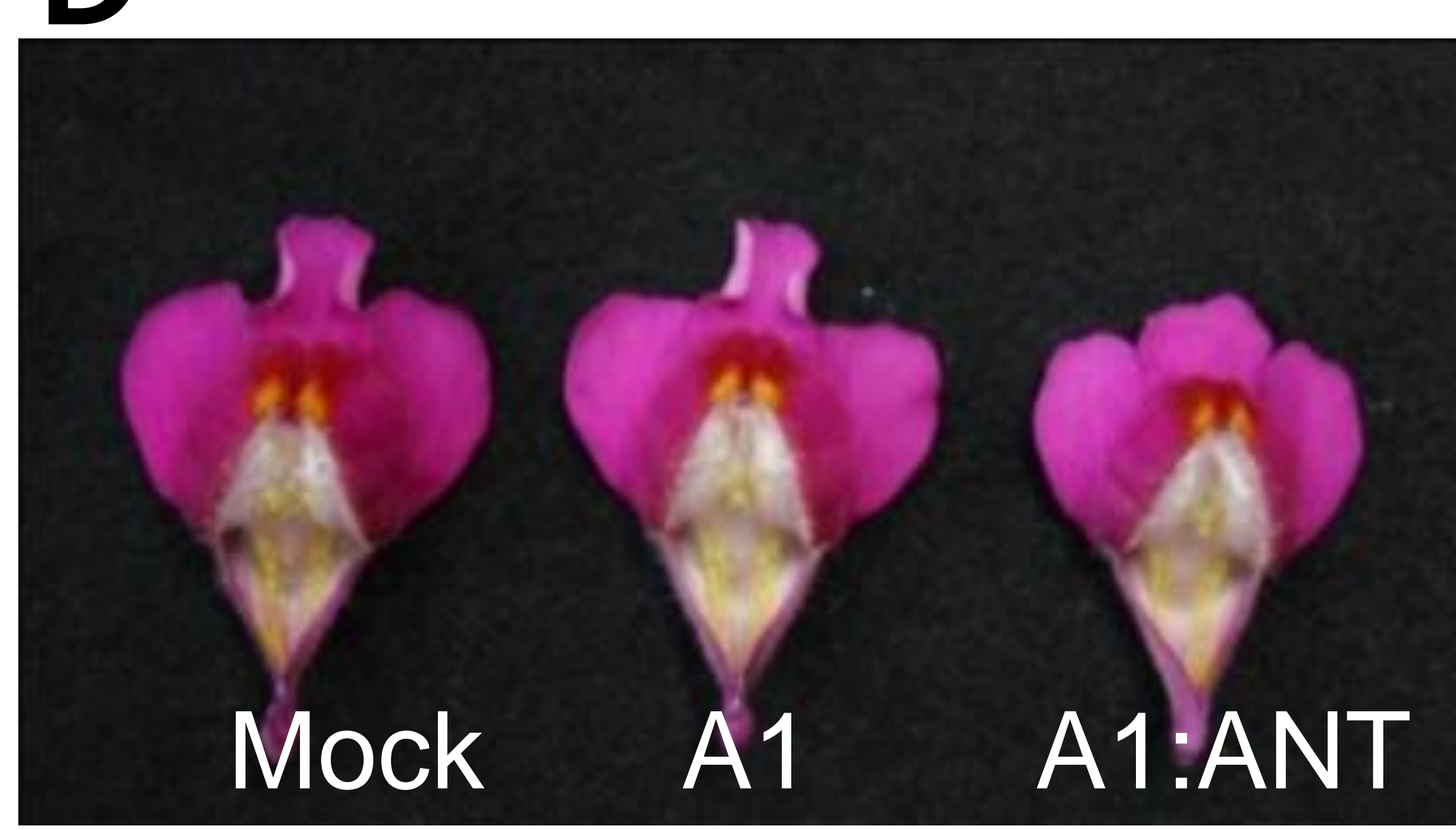

F

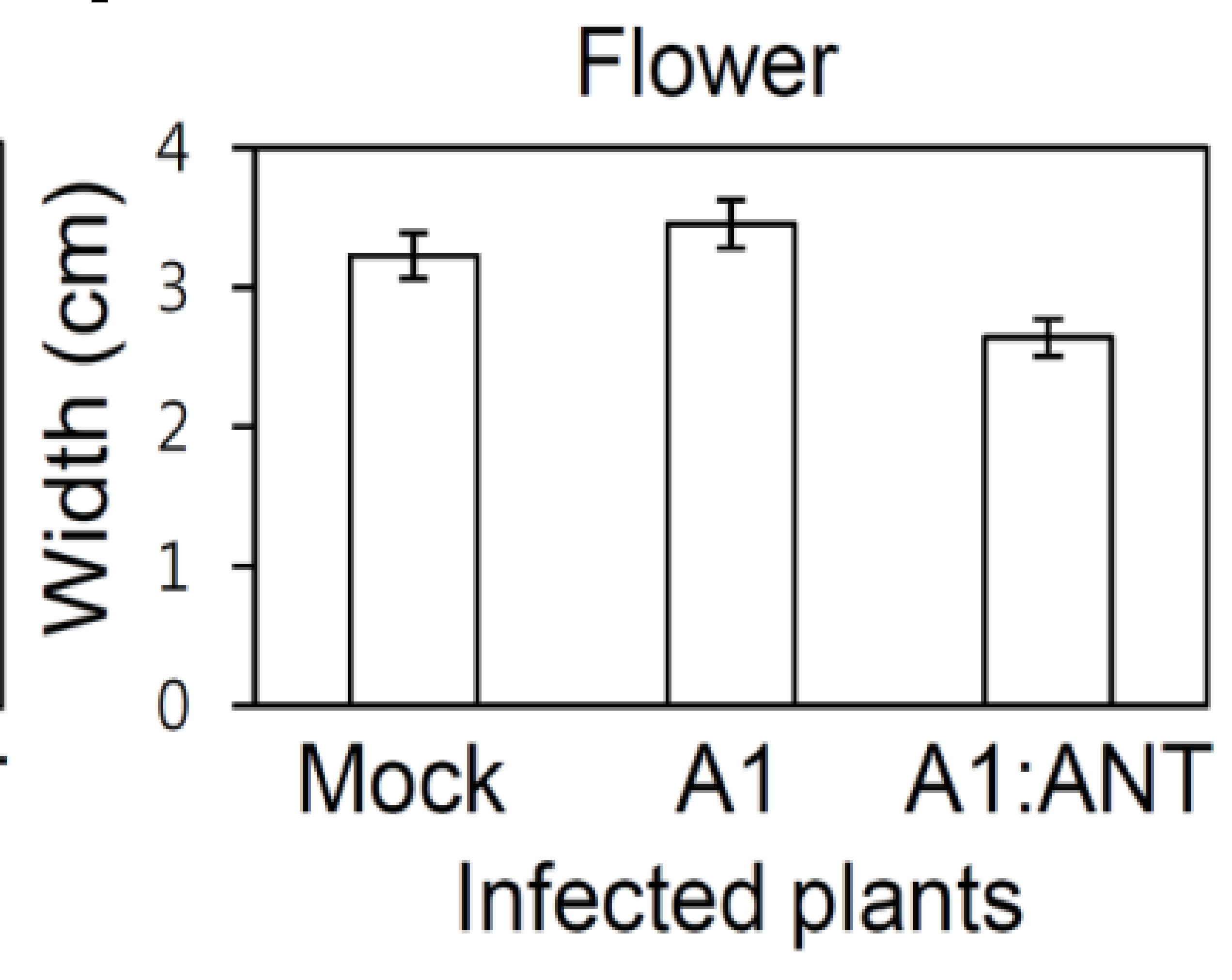

I

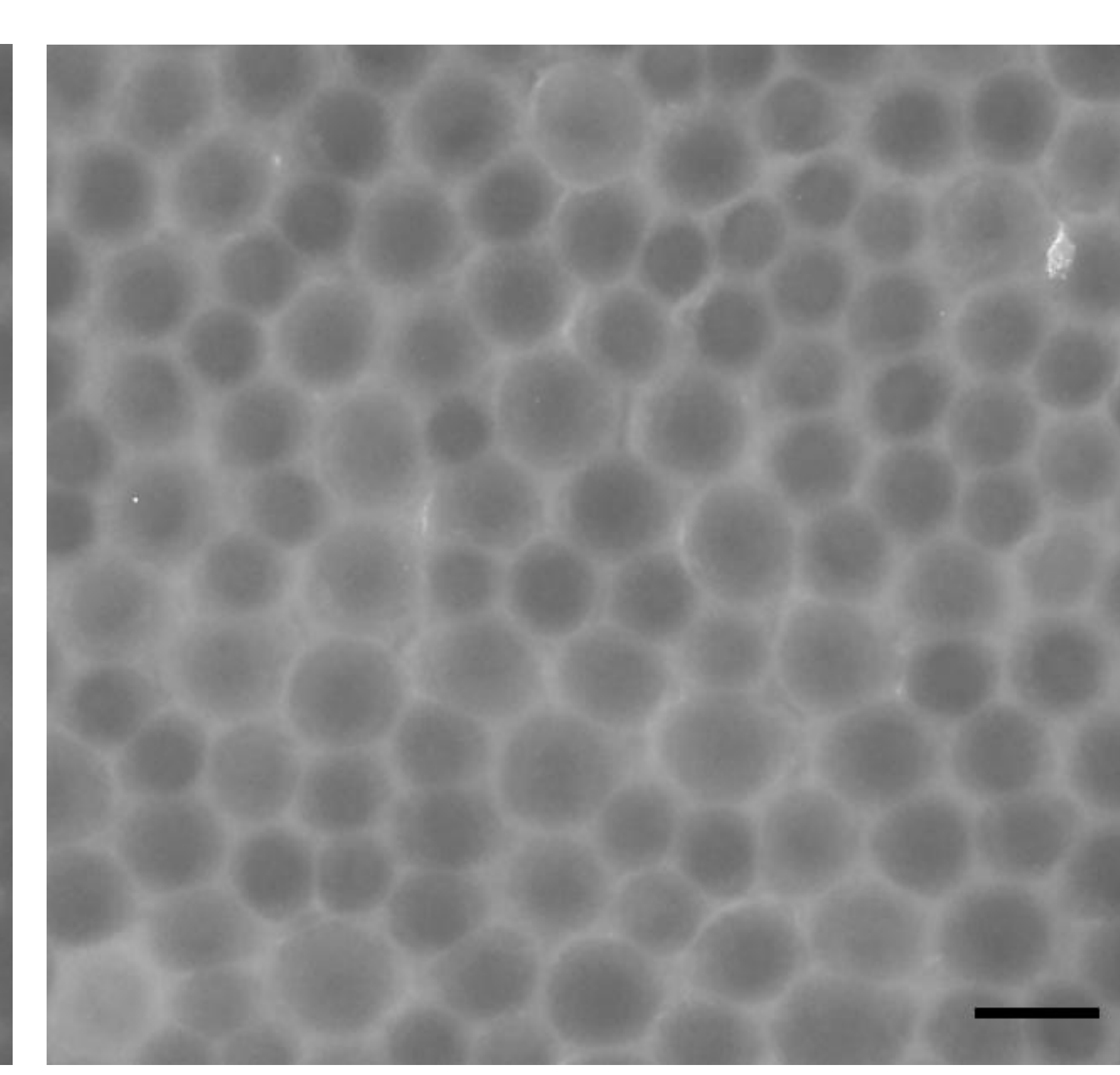

A1

A1:ANT 
A

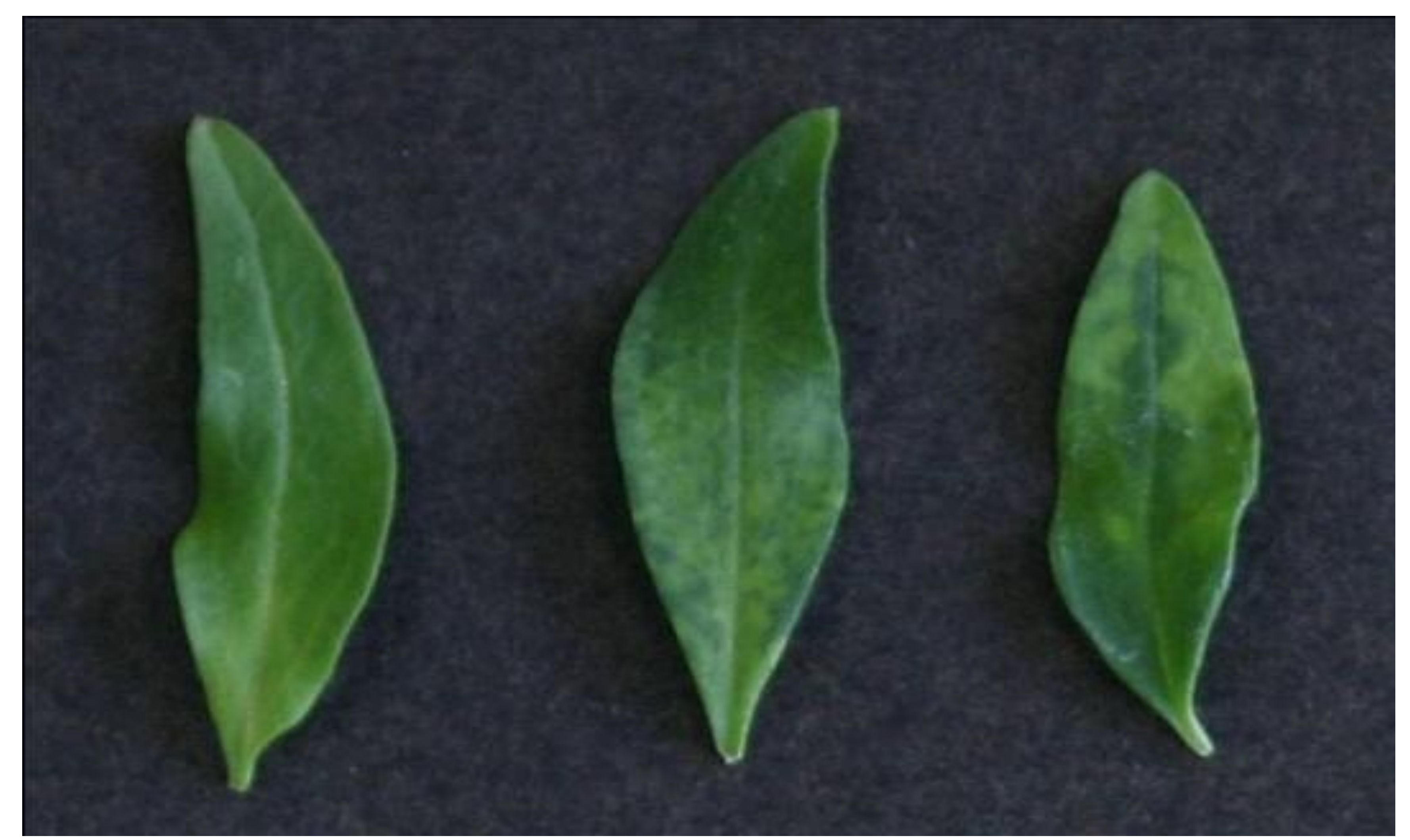

Mock

A1 A1:ANT

B

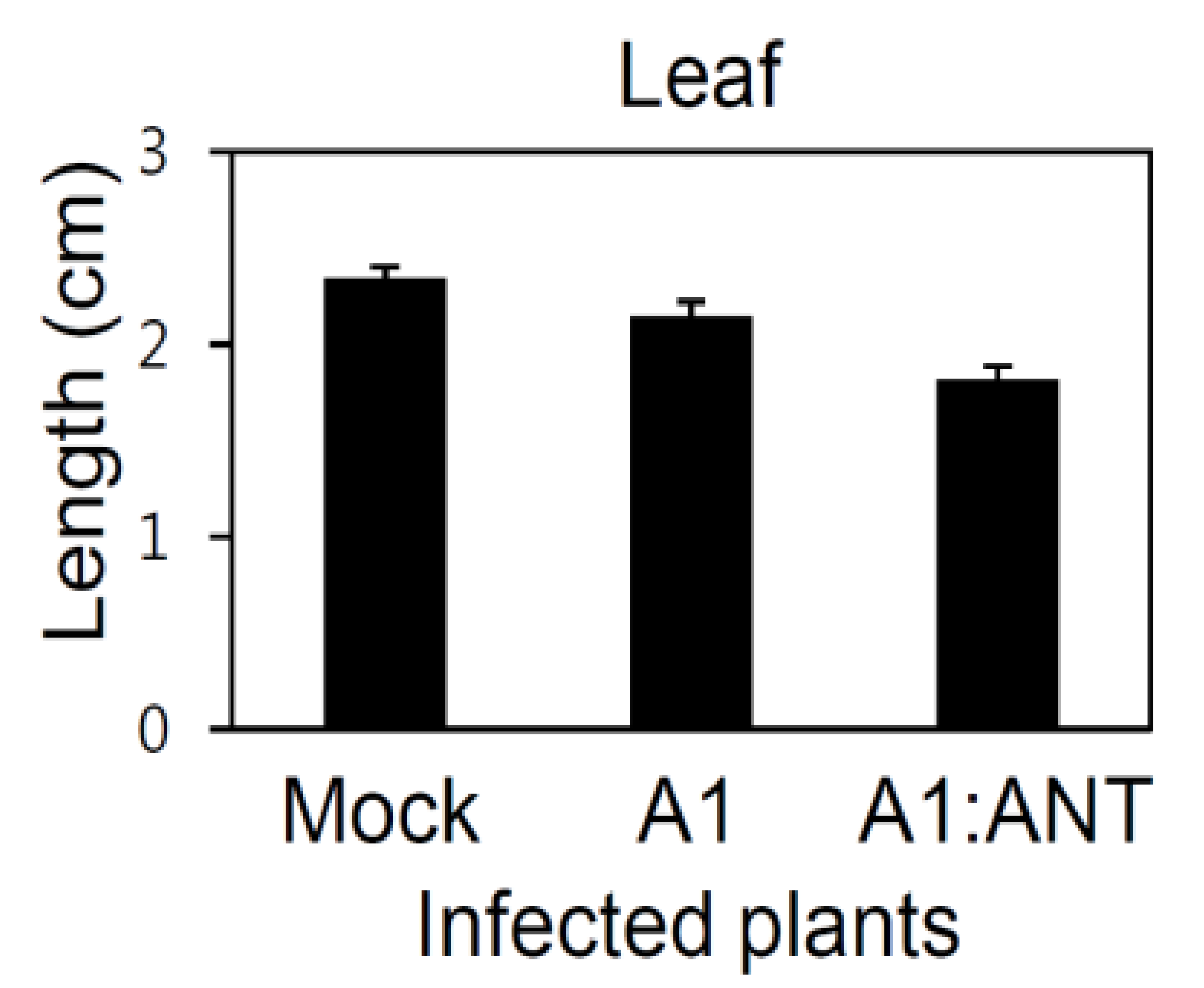

C

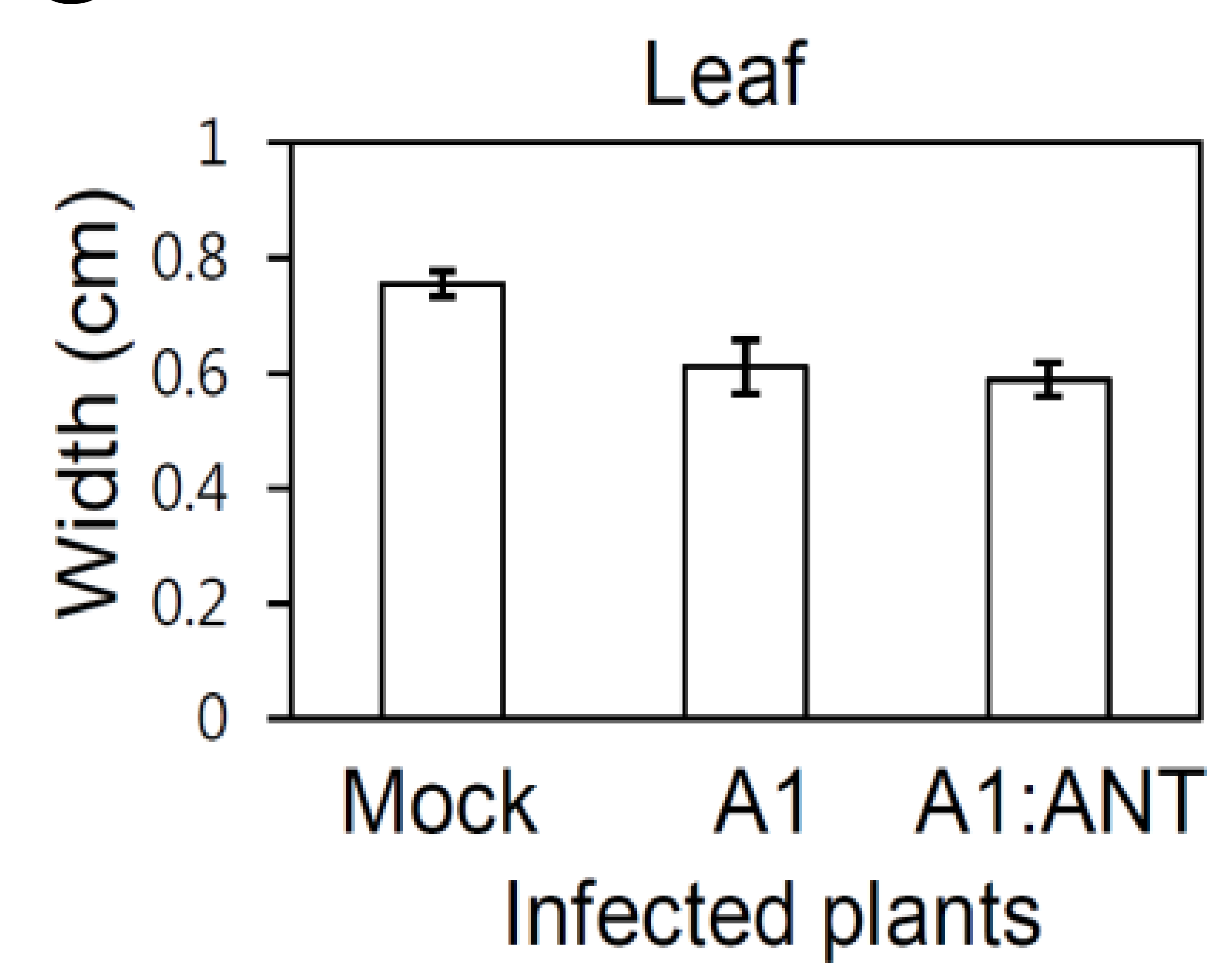

D E

F

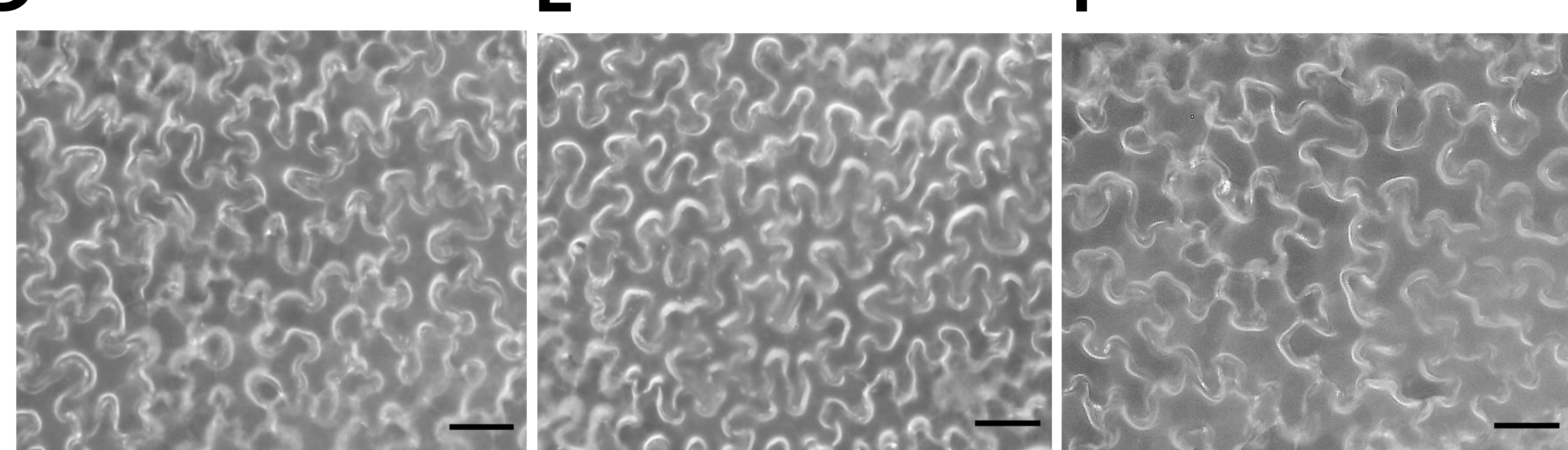

Mock

A1

A1:ANT 
A

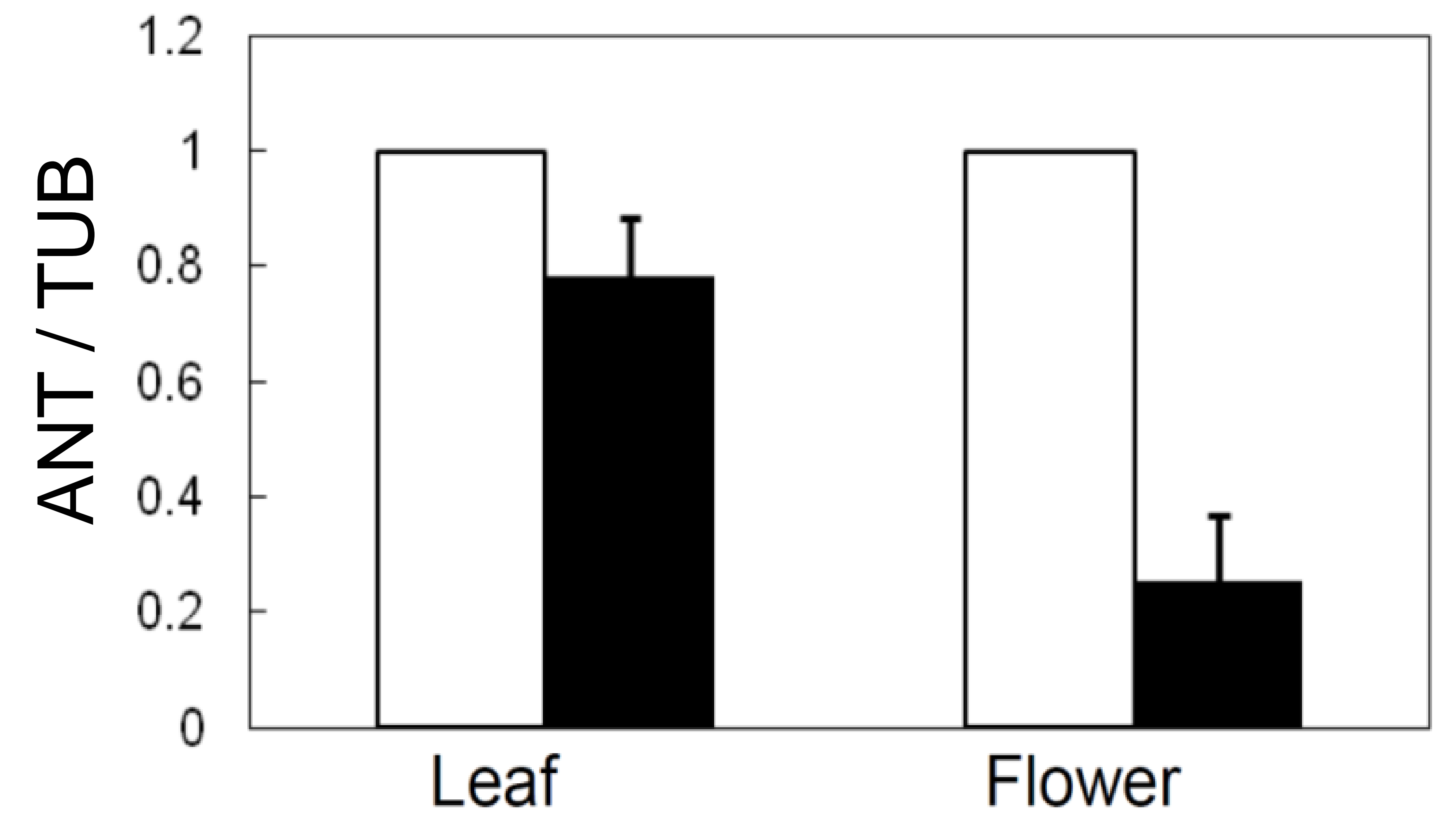

B

Mock A1 A1:ANT

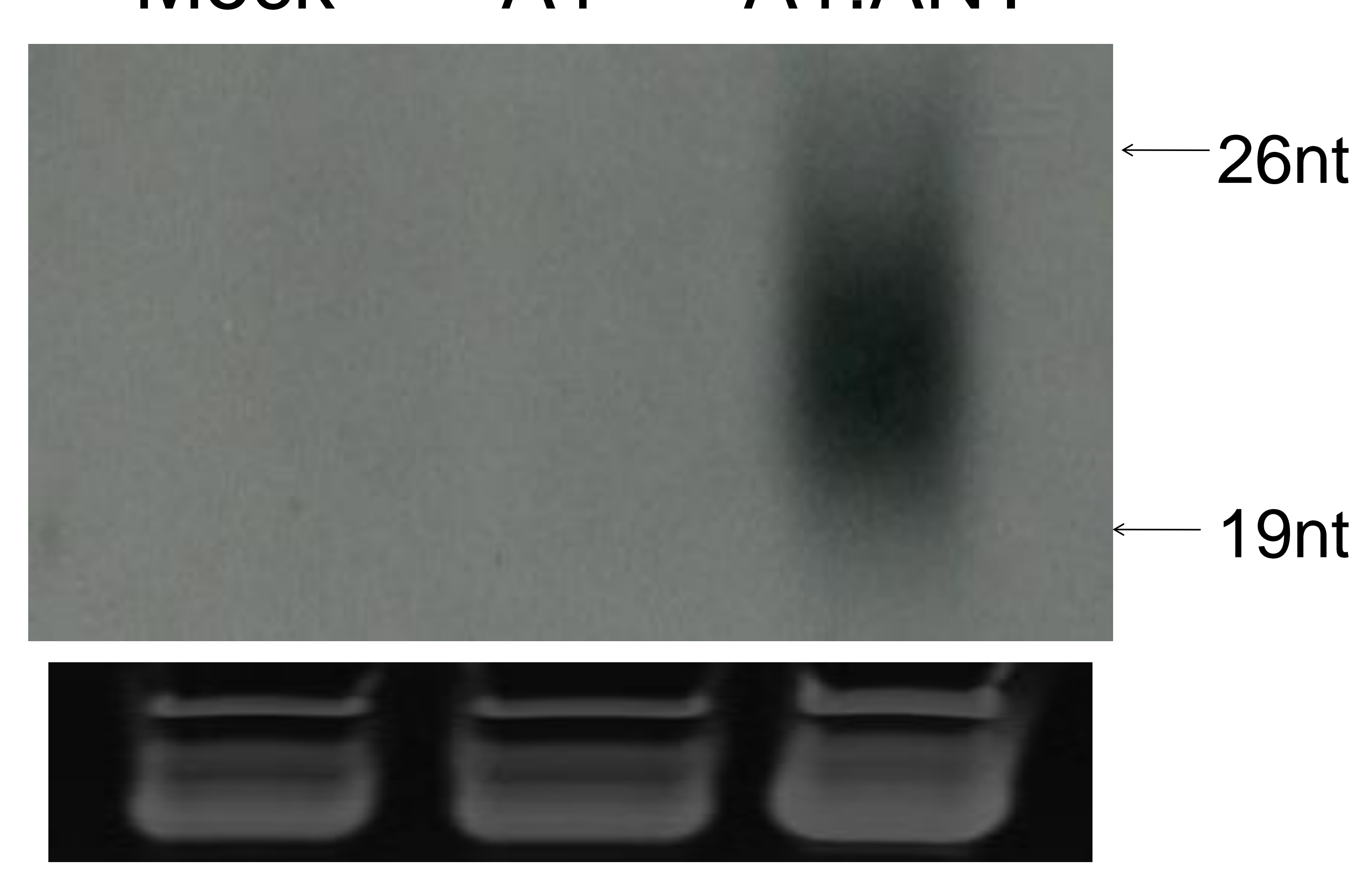

5s rRNAs \& tRNAs 